\title{
Shaping the Future of Research: a perspective from junior
}

\section{scientists [version 1; peer review: 1 approved, 1 approved with}

\section{reservations]}

\author{
Gary S. McDowell ${ }^{*}$, Kearney T. W. Gunsalus ${ }^{2 *}$, Drew C. MacKellar ${ }^{3}$, \\ Sarah A. Mazzilli4, Vaibhav P. Pai1 ${ }^{1}$, Patricia R. Goodwin5, Erica M. Walsh6, \\ Avi Robinson-Mosher ${ }^{7}$, Thomas A. Bowman ${ }^{8}$, James Kraemer ${ }^{9}$, Marcella L. Erb ${ }^{10}$, \\ Eldi Schoenfeld ${ }^{11}$, Leila Shokri12, Jonathan D. Jackson ${ }^{13}$, Ayesha Islam ${ }^{14}$, \\ Matthew D. Mattozzi7, Kristin A. Krukenberg³, Jessica K. Polka(iD3

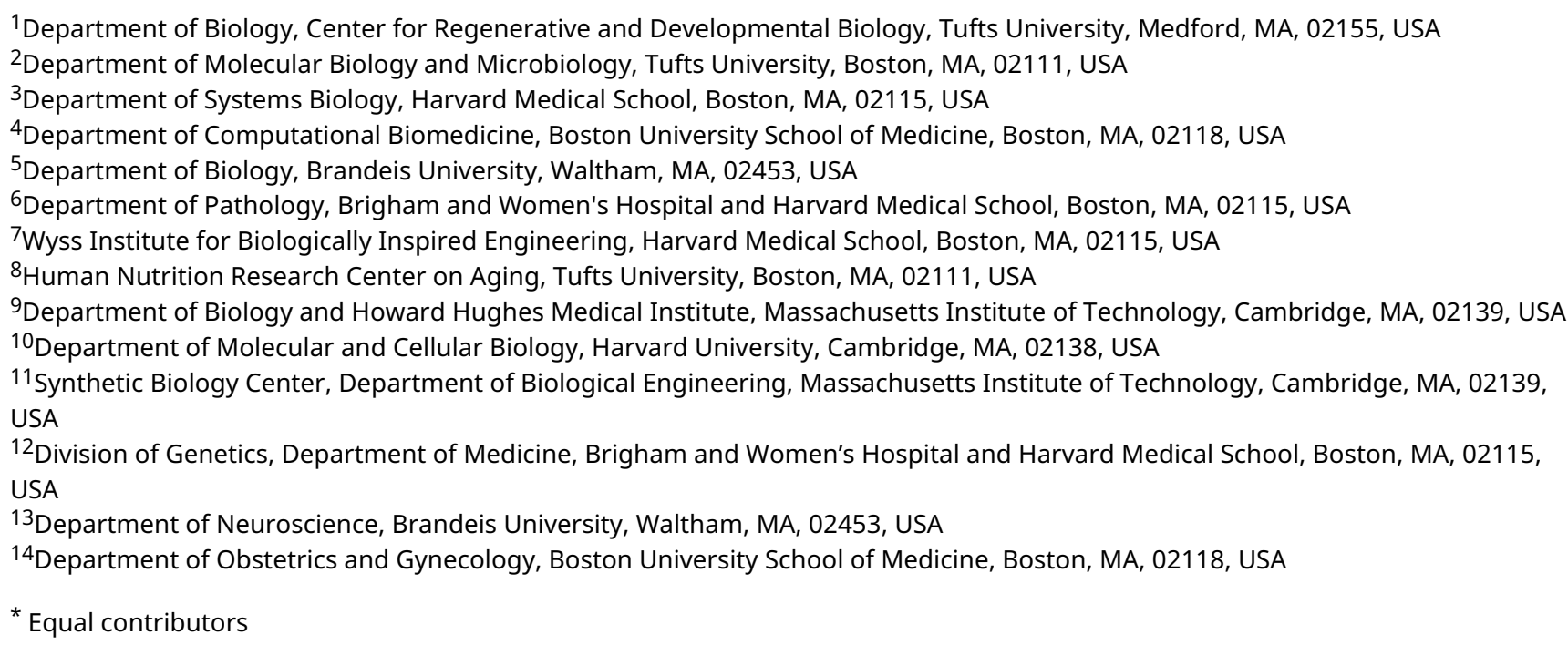

V1 First published: 28 Nov 2014, 3:291

https://doi.org/10.12688/f1000research.5878.1

Latest published: 09 Jan 2015, 3:291

https://doi.org/10.12688/f1000research.5878.2

\section{Abstract}

The landscape of scientific research and funding is in flux and affected by tight budgets, evolving models of both publishing and evaluation, and questions about training and workforce stability. As future leaders, junior scientists are uniquely poised to shape the culture and practice of science in response to these challenges. A group of postdocs in the Boston area who are invested in improving the scientific endeavor, planned a symposium held on October $2^{\text {nd }}$ and 3 rd, 2014, as a way to join the discussion about the future of US biomedical research. Here we present a report of the proceedings of participant-driven workshops and the organizers' synthesis of the outcomes.

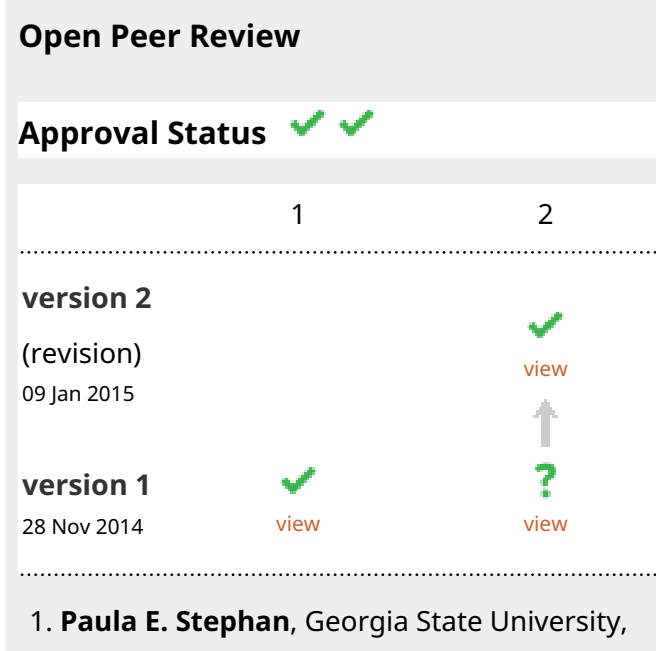

Page 1 of 21 
Keywords

biomedical research , funding , training , publishing

This article is included in the Research on

Research, Policy \& Culture gateway.

This article is included in the Future of Research

Couture of

(FoR) collection.
Atlanta, USA

2. Kenneth D. Gibbs Jr., National Cancer

Institute, Washington, USA

Any reports and responses or comments on the article can be found at the end of the article.

Corresponding authors: Kristin A. Krukenberg (kristin_krukenberg@hms.harvard.edu), Jessica K. Polka (jessica.polka@gmail.com)

Competing interests: No competing interests were disclosed.

Grant information: The author(s) declared that no grants were involved in supporting this work.

Copyright: @ 2014 McDowell GS et al. This is an open access article distributed under the terms of the Creative Commons Attribution License, which permits unrestricted use, distribution, and reproduction in any medium, provided the original work is properly cited. Data associated with the article are available under the terms of the Creative Commons Zero "No rights reserved" data waiver (CC0 1.0 Public domain dedication).

How to cite this article: McDowell GS, Gunsalus KTW, MacKellar DC et al. Shaping the Future of Research: a perspective from junior scientists [version 1; peer review: 1 approved, 1 approved with reservations] F1000Research 2014, 3:291 https://doi.org/10.12688/f1000research.5878.1

First published: 28 Nov 2014, 3:291 https://doi.org/10.12688/f1000research.5878.1 


\section{Executive summary}

The Future of Research Symposium, held in Boston in October 2014, was born out of a desire on the part of junior scientists to influence discussions about the future of biomedical research in the United States. Current trainees in academic research represent a talented pool of people contributing to scientific progress. This pool, however, is far larger than the current system is able to support in the long term. As structural forces governing the funding and administration of science push many graduate students and postdocs out of research, the public funds supporting their training are poorly repaid.

We view the current policy makers' reluctance to invest in science as a short-sighted and potentially catastrophic mistake. Furthermore, the current distribution of funding priorities and the way that funding agencies, universities, and journals reward scientists leads directly to inefficiencies within the conduct of research. While scientists continue to advocate for increased funding, they must also create a scientific enterprise that is sustainable with the current resources. A sustainable long-term investment in science, and an appreciation of the young people who carry it out, are essential to the long-term economic and social interests of the US. Specifically, the hyper-competition that we have all experienced, which stunts scientific curiosity and productivity, breeds fabrication and carelessness in the publication of data, and leads to a waste of valuable resources and intellectual capital, must be alleviated. In all of our discussions, we have kept two goals in mind: maximize the potential for wide-ranging and fundamental scientific discovery; and minimize the loss of talented young researchers who can contribute greatly to science.

In addition to voicing our concerns, we junior scientists recognize that we need to become more aware of the issues facing the research enterprise, comprised of academia, industry, publishing, and government. To accomplish this, the initial sessions of the symposium consisted of a series of talks and panel discussions from leaders who have been outspoken about the challenges that science faces. These were followed by workshops designed to elicit the opinions and ideas of participants, largely postdocs and graduate students, on problems and solutions surrounding training, the structure of the research workforce, funding, and incentives and rewards in science. We present the outcomes of those discussions in this report, which represents a united voice of young biomedical scientists, conveying our concerns about the sustainability of the research enterprise and our hopes for change.

From the many ideas presented in the workshops and continued discussions among the organizers, we have distilled the following three principles to guide future activities towards scientific reform:

1. We recommend increased connectivity among junior scientists and other stakeholders to promote discussions on reforming the structure of the scientific enterprise.

2. We advocate for increased transparency. This includes the number and career outcomes of trainees, as well as the expectations of the balance between employment and training in individual postdoctoral appointments.
3. We call for an increased investment in junior scientists, with increased numbers of grants that provide financial independence from Principal Investigator (PI) research grants, and increased accountability for the quality of training as a requirement of funding approval.

Junior scientists must take a larger role in engaging with these issues. As the engine of academic research, junior scientists must be given a voice fitting their role as major stakeholders in the scientific enterprise. Equally, junior scientists must be educated about their role so that they have the context necessary to make a wellinformed contribution and to effectively advocate for their interests. By bringing our concerns into the conversation that guides policy, the dialogue will be enriched with diversity and fresh perspectives. We encourage our peers to continue this conversation, engage their colleagues, and to get involved in shaping the Future of Research.

\section{Genesis of the Future of Research Symposium}

" "The government should provide a reasonable number of undergraduate scholarships and graduate fellowships in order to develop scientific talent in American youth. The plan should be designed to attract into science only that proportion of the youthful talent appropriate to the needs of science in relation to the other needs of the nation's high priority". And I think that is one of the places where we have in biomedical science gone astray".

Shirley Tilghman, quoting Vannevar Bush, at a meeting of the President's Council of Advisors on Science and Technology (PCAST), September 19 2014, ("PCAST Meeting 2014", 2014).

A large portion of the nation's science and engineering research is carried out by graduate students and postdocs. Because of this, the current culture of training places a heavy emphasis on research and publications, at the expense of "soft skill acquisition" or career development.

In the US, pre-doctoral training in the biomedical sciences takes 6.5 years on average (Figure 3 of (Biomedical Research Workforce Working Group, 2012)), and includes research experience culminating in a $\mathrm{PhD}$ dissertation. This process is overseen by a committee of 3-5 faculty members and requires the development of some core skills.

In contrast, it is notoriously difficult to determine how many postdoctoral scholars there are, let alone what kind of training they are or should be receiving. The National Institutes of Health (NIH) and the National Science Foundation (NSF) define a postdoctoral scholar as "an individual who has received a doctoral degree (or equivalent) and is engaged in a temporary and defined period of mentored advanced training to enhance the professional skills and research independence needed to pursue his or her chosen career path" (Bravo \& Olsen, 2007). Most postdoctoral "trainees" conduct research under the supervision of a single Principal Investigator (PI), and there are no explicit guidelines to determine what training a postdoc should receive or when this training is complete. In reality, postdoctoral research is often not a training period at all, but a 
time when experienced junior researchers contribute significantly to the goals of a PI's grant. There is no expectation of specific training, and no defined period in which the training takes place: "training" ends only when the postdoc takes another job.

In spite of the number of years spent in pre- and postdoctoral training, only a handful of scientists feel that they are adequately prepared for any job other than conducting research. Many feel they are unaware of what jobs they should be training for, let alone what skills those jobs require. One common complaint is that scientists are not being prepared for non-faculty positions, yet the number of new faculty who are unprepared for their non-research responsibilities (such as managing employees and budgets or teaching) suggests that graduate students and postdocs are not even being properly trained to become future faculty.

Where did all the graduate students and postdocs come from? While the number of US graduate students in biomedical science have increased from about 46,500 in 1993 (Table B-18 in (National Science Foundation, 1994)) to almost 71,000 in 2012 (Table 16 in (National Science Foundation, 2014)), the fraction of PhDs in life sciences in a tenure-track position 5 years post-PhD decreased from $17.3 \%$ (1993) to $10.6 \%$ (2010) (Table 3-18 in (National Science Board, 2014). There has also been a tremendous shift in the job market outside of academia over the past decades, with a general slowdown and even contractions in government and industry. This situation has long been deemed unsustainable by many senior academics (Bourne, 2013a; Stephan, 2012a; Stephan, 2012b; Teitelbaum, 2008).

With the number of graduate students increasing faster than the number of faculty positions (Figure 1 in (Schillebeeckx et al., 2013)), it is unsurprising that the NIH estimates that the number of postdoctoral researchers also doubled during that time. However, estimates of the number of postdocs vary drastically. The National Research Council puts the number of postdocs at just over 50,000 (National Research Council (US) Committee to Study the National Needs for Biomedical, Behavioral, and Clinical Research Personnel, 2011), but the NIH states that this could be under-estimated by as much as a factor of two (Biomedical Research Workforce Working Group, 2012). According to a recent report by the National Postdoctoral Association (NPA), the NPA's 167 member institutions alone estimate that their postdoc offices serve about 79,000 postdocs (Ferguson et al., 2014).

Where do graduate students and postdocs actually go? Data from the NSF Survey of Doctorate Recipients suggests that the US-trained biomedical PhDs "who do the longest postdocs are the ones who go on to tenure-track academic research careers" (Rockey, 2012). However, in spite of the number of scientists remaining in long postdocs in the hopes of landing a tenure-track faculty position, the data show clearly that academia is an "alternative" career, not the default. In 2010, less than $15 \%$ of US-trained science, engineering and health sciences postdocs had obtained a tenure-track faculty position within 5-7 years of completing their PhD (Sauermann \& Roach, 2012). The rest of the job market encompasses many fields that are expanding and can benefit from the trained minds of PhDs and postdocs. These include (but are not limited to): consulting for life sciences, biotech and biopharmaceutical industries, sales and marketing of technologically advanced products, regulatory affairs, science policy, science communications, and intellectual property.

Even though the majority of postdocs will do something other than become tenure-track faculty members, the default assumption of many PIs (and their mentees) remains that graduate students and postdocs will follow their mentors' career trajectory and acquire an academic faculty position at a research-intensive institution. The data show that by the end of their $\mathrm{PhD}$ training, only $50 \%$ of graduate students want to become academics, and that expectations change over time: a faculty position becomes less attractive over the course of a $\mathrm{PhD}$, in spite of active encouragement by advisors (Sauermann \& Roach, 2012).

Thus, many junior scientists want, and most will obtain, non-faculty jobs. However, few young scientists and their faculty mentors know what careers are actually available, let alone what skills those jobs require or how to obtain them. The mismatch between scientists' career expectations and the realities of the job market has led to extended occupancy of postdoc positions and highly inflated expectations from academic employers for prior productivity.

\section{How does the funding system contribute to workforce and training problems?}

In the US, the funding system has had a profound impact on the structure of universities and academic and applied research departments, and how the time of principal investigators and young scientists is spent.

As early as 2003, the rapid increase in funds over the previous decade was generating questions about where trainees would end up in the absence of a concomitant increase in academic positions (Russo, 2003). In response to these concerns, there have been calls for institutions to become more responsible for funding "hard-money" faculty positions, and to increase NIH incentives for doing so, rather than relying on external sources of funding for "soft-money" positions (Alberts, 2010). These problems were left unresolved, however, and now that there has been a contraction in funding they have become immediate. For institutions and individual researchers attempting to make long-term decisions, financial uncertainty makes planning very challenging. It is clear that simply putting more money into the system would provide only a temporary fix, not a long-term solution to the systemic problems with academic research (Alberts et al., 2014; Martinson, 2007).

\section{What's wrong with competition?}

An assumption of many industries is that increased competition between groups or individuals yields largely beneficial results. However, academic science in the US was essentially founded on Vannevar Bush's principle of the "supreme importance of affording the prepared mind complete freedom for the exercise of initiative" (Bush, 1945). These two principles are incompatible.

Indeed, we believe that the problems caused by the current unsustainable workforce are threatening the very foundations of scientific research. The high stakes and low expectations of success prevalent throughout biomedical research, from grant applications to hiring decisions, promote academic dishonesty (Lang, 2013). Also, success 
in grant applications and career progression relies heavily on publications (van Dijk et al., 2014). This can lead to hyper-competition for "high-impact" publications and in some recent cases, a lack of truth in publishing (Nosek et al., 2012; Sovacool, 2008). Competition also encourages scientists to present data in the most optimistic light, and to include only data that lead to a clean and understandable conclusion. As postdocs, we see and experience these pressures first-hand. The pressure to publish needs to be balanced with incentives for rigorous and honest scientific communication.

However, dishonesty is not the only problem threatening the integrity of academic literature. Part of the scientific endeavor is to provide checks and balances, reproduce results, and highlight when reproducibility fails. However, it is difficult (and unrewarding) to publish the results of replicative experiments or negative data, and there is a worrying trend in the lack of reproducibility in some forms of analysis; this issue was recently highlighted with regard to the widely-used technique of fluorescence-activated cell sorting (Hines et al., 2014). Some journals have made a call specifically for papers reporting negative data, and there are indications that the NIH may be looking to drive more studies testing whether data can be reproduced (Collins \& Tabak, 2014).

Hyper-competition can also discourage creative thinking and risktaking, strong foundations of the scientific endeavor (Alberts et al., 2014). Rather than grant applications for innovative, breakthrough science, we have observed that hyper-competition results in "safe" applications, driving incremental, slow improvements on existing knowledge. It blunts the blade of science, preventing it from piercing through existing ideas and paradigms to expose new frontiers.

\section{Junior scientists must join the debate}

A range of problems with the biomedical research system in particular have been the subject of increasing alarm in the scientific community (Alberts et al., 2014; Bourne, 2013a; Bourne, 2013b; Bourne, 2013c). While the focus has mostly been on US academic science, many of the problems are universal. These issues are not just relevant to those inside academia: due to their importance to national competitiveness, they are increasingly featured in the popular media as well (Harris, 2014a; Harris 2014b; Harris 2014c; Harris 2014d).

The public debate surrounding these issues has so far been led by senior members of academia (Alberts et al., 2014). One group that has yet to contribute significantly to the discussion is the largest group of researchers affected: graduate students and postdocs. Boston-area postdocs organized the Future of Research Symposium to raise awareness of the difficulties faced by young scientists and to provide a venue for further discussion and problem-solving during a set of interactive workshops.

We issued a call-to-arms to our peers to announce what we were doing, and to emphasize our view that young researchers should have a say in shaping the future direction of the research endeavor (McDowell et al., 2014a). To achieve our goal of giving a voice to the aspirations of young researchers, we synthesized the current issues that have been identified as obstructing the progress of scientific research into four focus areas: funding for biomedical research, training of the scientific workforce, the structure of the workforce, and incentives and rewards for scientists (McDowell et al., 2014c). Interactive problem-solving workshops honed in on each topic to explore the problems and propose solutions with the aim of formulating a response that we can provide to the larger scientific community. This document is the first to begin disseminating that response to foster and foment further discussion and action. Here we present the problems identified and tentative solutions suggested by participants in the workshops. We then discuss areas identified through ongoing discussions as requiring the most urgent action from young scientists to improve the Future of Research.

"To be creative...emphasize new possibilities by disclosing those hidden episodes of the past when, even if in brief flashes, people showed their ability to resist, to join together, occasionally to win".

Howard Zinn (Zinn, 2014)

\section{Survey of participants prior to the symposium}

In order to focus the aims of the workshops, participants were invited to complete an anonymous survey of their ideas about how science should be conducted and supported, and the problems they identified with the current system. In all, 409 people responded to the survey, although not all offered a response to all questions (raw data are available in Appendix 1). Respondents were primarily postdocs and graduate students, but also included administrators, faculty, industry, research assistants and undergraduates (Figure 1). The survey included five short-answer questions; while these responses are not amenable to quantitative analysis, we have summarized them below.

\section{"What is the biggest problem facing the way science is conducted today?"}

Answers focused on several key points, listed here by the frequency with which they were mentioned, starting with the most commonly cited problems.

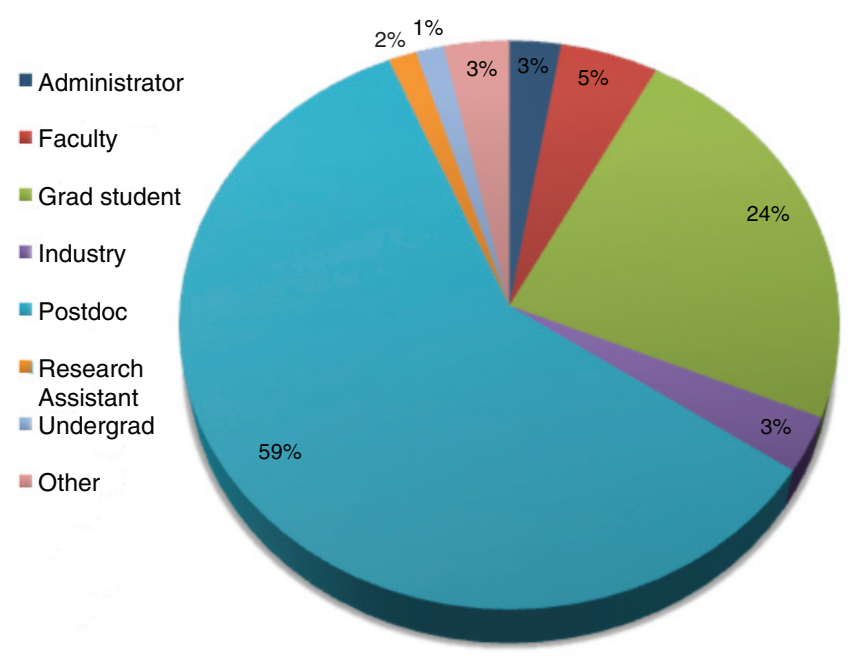

Figure 1. Breakdown of the self-identification of respondents in the Future of Research Symposium registration survey. 
- In the US, funding for basic science is inadequate to support long-term economic growth.

- The quality of the scientific results being produced is compromised by the current structure of research funding and execution.

- The research environment at present selects for proficiency at securing funding and publishing high-profile positive results, rather than rewarding scientific skepticism, curiosity, and balanced presentation of sometimes complex results.

- The current funding system is unnecessarily bureaucratic and insufficiently transparent, reflecting temporary political whims, and the duration of NIH grants is too short to support the lengthy explorations necessary to accomplish truly novel, beneficial basic research.

- The number of enthusiastic scientists competing for scarce funding encourages counter-productive levels of competition.

- Existing publication models exacerbate the problems arising from the inefficiencies of funding and the promotion of talent; journals disseminate research results in a periodic, page-limited manner that is outmoded in the internet era.

- There were many concerns about mentorship, trainee freedom and related issues indicative of an imbalance between the supply of qualified scientists and the demand for sufficientlyfunded basic research positions.

"What behaviors should be encouraged in scientists?"

The most common responses to this question (most commonly mentioned first) included:

- Collaboration, meaning interdisciplinary teamwork between scientists in different institutions and fields, as well as across boundaries of status and seniority.

- Openness in data, reagents, and evaluation of each other's work.

- Integrity and ethical research practices, innovation, and risktaking.

- Critical thinking in the reporting and reproducibility of results.

- Greater outreach to the public to improve non-scientists' awareness of the most crucial results in recent research.

- Greater efficiency in the research process, as well as entrepreneurship, academic-industry partnerships, and more effective measurement of training and outcomes in basic research.

"What does ideal scientific training look like?"

The overall consensus from responses to this question focused on the importance of teaching scientists how to solve problems with scientific methods in an ethical fashion.

- Training should be consistent across institutions, be multidisciplinary, and be independent of the race, sexual orientation, gender, gender identity or expression, national origin or cultural identification of its participants, to promote a community of diverse intellects.
- Mentorship should involve close interactions between mentor and mentee and should include well-defined expectations for both parties.

- A common request was for job security amongst researchers. Suggestions for implementation included a restriction upon the total number of PhDs awarded, an expectation of retirement based upon the age of PIs, an increase in the number of staff scientist positions supported by federal research funds, and more rigorous evaluation of scientists across institutions, from the undergraduate to the principal investigator level.

\section{"What should be the purpose of government funding for} science?"

Respondents replied that government funding should balance an interest in both the long-term (basic) and short-term (applied) benefits of science.

- Industrial/commercial entities should assume responsibility for the advances that are most directly commercializable, while federal funding should address projects that are more prospective.

- Government funding should support public health and environmental health research that is otherwise not addressed by the immediate, private concerns of individual donors.

- To help support long-term research, some grants could be awarded to institutions, rather than individuals, to allow a community of researchers to decide among themselves which projects they find most meritorious.

- Within basic research, funding outcomes should be independent of expectations of immediate profitability. Many crucial advances within science have been made based on open-ended inquiry, driven by the curiosity of the individual personalities involved, and these contributions have subsequently proven essential to technical innovation.

Respondents also noted that excessive competition hinders collaboration and encourages non-productive duplication of experimental effort on select "hot topics". The competition among qualified personnel for independent jobs is also highly inefficient in terms of wasted human capital.

"The NIH has lost approximately $25 \%$ of its purchasing power over the last 10 years. Should the scientific workforce (i.e., make-up of the labor force: grad students, postdocs, senior scientists, etc.) adapt to this change, and if so, how?"

Only $13 \%$ of graduate students, $16 \%$ of postdocs, and $18 \%$ of faculty respondents suggested that the workforce should not adapt to the existing funding trends. Of those opposed to adaptation, established researchers (faculty) considered it more important to ignore fluctuations in funding. Most respondents suggested adaptation, using varying strategies. Several faculty respondents focused their attention upon lobbying congress and turning to public outreach in order to convince our fellow citizens of the importance of funding basic biomedical research. Other suggestions included:

- Reaching out to alternative funding sources, including state, local, and non-profit donors. 
- Instituting longer timelines for approved grants.

- More direct funding by universities for employee researchers, encouraging smaller labs with more direct PI-trainee oversight.

- Greater understanding that non-academic careers are actually the major outcome for $\mathrm{PhD}$ holders, and support and encouragement for students and trainees who enter such careers.

- More transitional funds for entrepreneurial research and private-public partnerships.

- Changing the ratio of academic lab personnel between grad students, postdocs, technicians, and senior scientists.

The responses to this question were predominantly in favor of reducing the number of trainees per permanent position available in basic research, to steer funds towards more permanent positions, to seek alternatives to traditional funding sources (including private and nonprofit sectors), and to encourage greater regulation at the institutional and lab levels to address the efficiency of spending relative to the scientific research benefit produced.

Overall, the respondents' concerns and criticisms centered on a few key themes; however, there was disagreement regarding which issues are most important to the future of groundbreaking and sustainable science. We considered these suggestions indicative of a general dissatisfaction with the current research paradigm, but not necessarily prescriptive of specific and comprehensive solutions. The output of this survey is informative in gauging the general opinion of educated, disciplined, and curious people pursuing science in the US. Practical adjustments to academic science were discussed in the workshops, described in the following sections.

\section{Participant-led Workshops at the Future of Research Symposium}

Workshops were designed to allow participants to discuss issues identified as obstructing the progress of scientific research. Each workshop was overseen by three to four moderators from the organizing committee who provided some background on the current system and posed the specific objective for each session. The four objectives were to ask:

- How can trainees be better prepared for careers in science in 2014 ?

- How should the supply of postdocs and graduate students be matched to the demand for jobs in order to create a sustainable workforce?

- How can the funding of academic research be structured to promote desired outcomes such as the discovery of basic knowledge, finding applications of knowledge for the betterment of society, and training the next generation of scientists?

- How can the current system of incentives be fixed so that scientists and institutions are rewarded for the behaviors that are believed to support good science?

Workshops were broken down into two separate 90-minute sessions. The number of participants per topic per session was typically between 20 and 30. Individual participants were asked to write down the perceived problems with the current system on post-it notes and to post them on the wall. Working as a group, participants categorized these individual responses and identified major themes. Participants were then asked to individually write down possible solutions to the identified problems. This was once again done on post-it notes. Solutions were categorized according to the level of implementation, ranging from actions that can be accomplished by individual graduate students and postdocs to those requiring action from society as a whole. If time permitted, participants voted on solutions they found most compelling and discussed the pros and cons of these solutions further. Generally, there was not sufficient time to discuss any potential solutions in depth. We view these sessions primarily as a way to begin debate, not to end it.

The workshops identified a large number of problems and potential solutions, many of which were raised repeatedly, though the immediate topic of conversation varied. In the following sections, we present lists of proposed solutions, without necessarily endorsing each possible solution, together with a few common themes distilled from each workshop. The raw data for each workshop can be found in Appendices 2A-D.

\section{Training for careers in science in 2014}

\section{Problems identified}

Participants identified problems with the current training system in the following key areas (Appendix 2A):

Culture of academia-focused training: The prevailing view of training focuses heavily on academia, where few scientists can obtain positions. This creates a sense of failure for those leaving academia.

\section{"[Young scientists have the] feeling there is no way to exit [academia] positively".}

Absence of awareness of non-academic job opportunities: Scientists have limited knowledge of careers outside of academia that require scientific training. They are not aware of the kinds of jobs they may be qualified for; the skills these different jobs may require; and how to successfully apply for these jobs.

"[Scientists are] unaware that careers in science exist (outside of academia)".

PIs are not equipped to advance their mentees' careers: PIs have little incentive to act as a mentor for a trainee's career development, and limited training that would make them competent to do so. "For a lot of mentors, it's not a priority to engage in your
career path".

Informal training leads to inconsistent training: There is a lack of standardized training for any scientific career, be it academic or non-academic. PIs require multiple skills learned only from experience; current training was described as "spotty" and "overly specialized". Training standards are highly variable between institutions and research groups. 
"Training is not formalized (expected to pick up stuff along the way)".

Lack of professional skills training: Current training fails to teach skills that can be applied to both academic and non-academic careers, including people management, networking, writing, and presentation skills. Scientists learn to conduct research, but not to manage a research group.

"Lack of "real world" professional skills".

Little or no training on transitioning to industry: There is a dearth of training about how to transition from academia to industry. There are too few internship programs providing experience in industry.

"You need to know someone in industry to get a job there".

\section{Proposed solutions}

\section{Individual graduate students and postdocs}

- Graduate students and postdocs can identify the skills they need to develop (such as via the my Individual Development Plan (myIDP) tool (Fuhrmann et al., n.d.)), then collaborate with each other and with graduate programs and postdoctoral offices to acquire training.

- Postdocs should advocate for themselves, network with each other, and provide mentorship to each other.

\section{PIs and research groups}

- We must correct the misconception that all scientists will pursue an academic career.

- PIs should allow time for career development; recent data suggests this will not detract from research productivity (Rybarczyk et al., 2011; Strategic Evaluations, Inc., 2014).

\section{Institutions}

- Institutions should make adequate, appropriate training available and insist that PIs allow attendance. "Adequate, appropriate training" should enhance the professional skills that graduate students and postdocs have identified as important for their chosen careers.

- Institutions should develop teaching and industry opportunities.

- Institutions could create networks that allow for past, current and future trainees to communicate about careers.

\section{Funding agencies and the scientific community}

- Availability of adequate, appropriate training should be mandated across all institutions.

- Grant incentives should be used to encourage PIs to facilitate adequate training.

\section{Conclusions}

The current culture of training places heavy emphasis on research and publications, leaving little time for "soft skill" or career development.
Postdoctoral "training" is a misnomer: as one participant put it, "If you're going to call me a trainee, then train me".

Rather than force everyone to be trained for the same (academic) career path, institutions should provide opportunities for trainees to acquire skills that are useful in multiple career paths, and PIs should be required to allow trainees access to these training opportunities.

Postdocs were consistently called "the lost people" and "the invisible people". Postdocs do not yet have a coherent voice, and we must change this. Postdoctoral associations should be advocating for access to training, both in provision and time allowance, in their institutions. The National Postdoctoral Association should have a stronger voice in advocating for postdoctoral training at a national level. Trainees should involve themselves with their learned societies to influence policy. Finally, researchers should be involving the wider public: to describe what can be given to society, to demonstrate their value, and also to highlight the waste of human capital and taxpayer money that goes into funding inadequate training.

\section{Towards a sustainable workforce}

\section{Problems identified}

Participants identified problems with the structure of the workforce in the following key areas (Appendix 2B):

Structure of the system: PIs currently train junior scientists (multiple trainees per PI) in their own image, that is, for a career in academia, though only a small minority will obtain tenure-track faculty positions. Most PIs know little about non-academic careers, even though these comprise the majority of future careers for today's postdocs. These non-faculty careers are often still looked down upon by those in academia. There is little attention given to training for the careers that the majority of junior scientists will eventually pursue.

\section{"Structure of academic workforce is pyramidal/feudal, gener- ating too many trainees per PI".}

Use of graduate students and postdocs as cheap labor: Junior scientists are primarily treated as cheap labor rather than as participants in a well-rounded training program that prepares participants for a range of clearly identified career options. Postdocs are conflictingly defined as trainees and employees in different situations, which is made possible by the lack of a standardized designation for postdocs and of a clear definition of their duties and responsibilities. There is also no oversight over the number of graduate students and postdocs and whether that number is appropriate given the perceived job market demand. Additionally, there was consensus that funding postdocs through research grants puts them in a vulnerable position and encourages low postdoc salaries allowing for the use of funds elsewhere.

"Postdocs are really hired to produce results, not scientists".

"Postdoc pay is low so PIs can hire more postdocs to generate more results".

"Lack of oversight for equal pay for trainees and to prevent exploitation". 
Lack of transparency: Problems with workforce sustainability are perpetuated by a lack of information and awareness about the situation, particularly amongst incoming graduate students who seek the increasingly rare academic careers that are still treated as the default career choice by many graduate programs.

"Complete lack of information on number of postdocs".

Funding and evaluation metrics: Current metrics of evaluation, which are based on the number and impact factor of publications, have resulted in a culture of hyper-competitiveness which discourages creativity, co-operation, risk-taking and original thinking.

“Risk taking not rewarded - No reward for leadership".

Lack of public awareness: Participants also felt a pressing need to make the general public aware of what a scientist really is and what she does, and to more effectively communicate the value of science to the US economy and to humanity as a whole.

"Lack of awareness about how the system operates and functions"

\section{Proposed solutions}

\section{Individual graduate students and postdocs}

- Each postdoctoral position should have a defined purpose, including a plan for enhancing the professional skills required in that postdoc's chosen career path.

- Graduate students and postdocs should be proactive about getting career information and carrying out self-evaluation, and discussing these with their mentors. They could also assemble their own career development committee, made up of mentors from various careers of interest.

- Graduate student and postdoc associations should collaborate within and between institutions to provide career information and training.

\section{PIs and research groups}

- PIs should be educated about career paths and trends in the biomedical workforce and how to effectively mentor students and postdocs for available jobs.

- PIs should be positively evaluated for diversity of successful career paths taken by their trainees, and not just on the number of trainees that they have placed in research-track careers.

\section{Institutions}

- Institutions should be transparent about the number and funding source of graduate students and postdocs.

- Admission of graduate students could take into consideration their career path and the objective of their training.

- Incoming graduate students should be educated about career options and provided with career development advisors.

- Institutions should offer career development courses in all areas of the National Postdoctoral Association core competencies
(The National Postdoctoral Association Core Competencies Committee, n.d.).

- Trainees should be encouraged to undertake internships outside the lab to gain experience in other career options.

- Permanent staff scientist positions should be created with funding structures that remove the competition between the staff scientist and cheaper postdocs or graduate students.

- Scientists' involvement in outreach, politics, and entrepreneurship should be encouraged.

\section{Funding agencies and the scientific community}

- There should be a standardized designation for all postdocs, irrespective of funding source.

- The purpose and responsibilities of postdocs should be clearly defined.

- Caps should be placed on the number of junior scientists per PI.

- All postdocs should receive at least the NIH minimum salary, with a geographical cost-of-living adjustment (US Office of Personnel Management, n.d.), and certain basic benefits.

- Funding for postdocs should not be tied to PI research grants.

- The hyper-competitive publish-in-high-impact-journals-orperish culture should be discouraged and risk-taking, leadership skills and creativity fostered instead.

- As a community, scientists should campaign to educate the public about who scientists are, what they do, and the value of their work.

- Within the academic scientific community, we should foster acceptance of non-academic career path choices.

\section{Conclusions}

There is a clear imbalance between the number of young scientists and the number of jobs available in research. This schism has been widening for the past few decades and producing stress on the scientific workforce which, if unaddressed, will result in a decline in the number of productive young scientists. The fundamental structural flaws in the system need to be addressed; otherwise, as we have seen in the past, simply increasing funding will only postpone and worsen the problem.

Young scientists need to be engaged in the debate about these changes and advocate for them. They need to come together in collaboration with institutions and the federal government to enforce and implement these changes with a clear discussion of all possible outcomes of these changes.

Ultimately the scientific enterprise will grow if the workforce supply and demand are balanced in a sustainable and dynamic fashion, with complete transparency. We can build a highly efficient and productive scientific enterprise if scientists, institutions, governments and industry are all involved and invested in making the necessary changes to the workforce. 


\section{Funding innovation and training}

Problems identified

Participants identified problems with funding in the following key areas (Appendix 2C):

Funding mechanisms were considered insufficiently diverse: Many participants were in favor of extending the time scales of awarded grants, and cited a need for alternative mechanisms to workhorse grants like the R01, that might permit research projects with alternative aims and organization. In addition, the NIH grant review cycle was seen as inefficiently slow and too bureaucratic to effectively support innovative work. Participants were frustrated at the way that funding agencies were considered to encourage incremental steps in research, thereby discouraging paradigm shifts. They also expressed concern that current funding mechanisms "kill novel ideas by emphasizing preliminary results“.

"Postdocs should be allowed to apply for grants [directly]"

"Evaluation of grants [is] tied to outdated/improper metrics"

Funding priorities fail to select for long-term productivity: Congressional and institutional trends heavily influence how research money is distributed, such that too much of the available funding is oriented towards ephemerally popular topics, while mature, yet important, research fields are neglected. Concerns were also raised that recent trends in funding favor applied research at the expense of basic research. These priorities undermine the quality and reproducibility of science that is vital to US interests.

“Funding rewards mainly 'high impact' publications, [producing] hypercompetitive and dishonest results".

"Emphasis on translation and the best 'new' idea, not reproducibility"

Grant evaluation processes disadvantage young researchers: Institutional leanings in funding agencies were perceived as resulting in funds that are highly centralized; with large grants being awarded to large, well-established labs.

"Bigger names/labs get multiple R01s whereas young/new PIs can't even get one".

"Grant success depends maybe too much on previous success; making it much harder for young scientists"

Funding allocation is not subject to post-award review of efficacy: Participants voiced concerns that the current funding paradigm does not lend itself to quantitative, objective analysis of the productivity or quality of research investments. Name recognition and impact factors were reported as weighing too heavily in singleblind study sections, resulting in funds being allocated unscientifically, with few studies of efficacy or predictors of outcome.

\footnotetext{
"Poorly audited"

"Money spent inefficiently (lack of negotiation, duplication of equipment)"
}

Approaches to funding were reported as contributing to problems in training and workforce sustainability: Participants noted an insufficient level of direct funding support for postdocs and graduate students, such as through training grants. They also indicated that, by focusing on research productivity alone, funding mechanisms fail to select for graduate and postgraduate education that would aid trainees in developing the skills that would contribute to success in academia or other environments. Funding agencies were also seen as contributing to the negative way that non-academic careers are viewed.

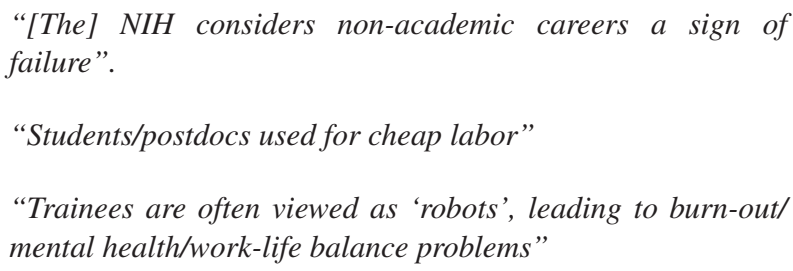

"Trainees are often viewed as 'robots', leading to burn-out/ mental health/work-life balance problems"

Grant application and administration processes are problematic: There was frequent concern regarding the bureaucracy and paperwork involved in applying for and administering grants. Participants characterized the level of effort required to complete auxiliary sections of grant proposals (i.e., outside of specific aims and experimental design) as inefficient, as well as the number of specialized personnel required to submit, review, and administer federal research grants. In addition, several participants found the current peer review system to be insufficiently transparent, and reported that study sections give too little feedback.

"Too much time spent by highest-level scientists writing grants".

Proposed solutions

Individual scientists and research groups

- Scientists should interact more directly with the public and the government to communicate the benefits of investment in research.

\section{Institutions}

- Staff scientists should be supported by grants in order to improve the continuity and accountability of research results within academic labs.

- Core facilities should be developed to reduce the resources and specialized expertise required in each lab, allowing smaller lab sizes.

\section{Funding agencies and the scientific community}

- We should analyze basic science funding and outcomes to determine how funding award mechanisms affect science.

- A greater diversity of funding mechanisms serving smaller labs, younger faculty, and even science enthusiasts within the general public, with an emphasis on encouraging shared, collaborative workspace and core facilities, should be developed.

- New metrics evaluating scientific productivity beyond simple impact factor should be established, along with more postpeer-review and scrutiny of results. 


\section{Conclusions}

Overall, we would characterize the output of this workshop as a call by young researchers for an increase in the efficiency and reproducibility of science by developing new measures of the quality of research output and of individual researchers' productivity, and incorporating these criteria into the approval of grants. Participants seemed to agree that this approach, along with some of the other recommendations indicated, would more adequately reflect the priorities of federally-funded science and encourage young researchers to continue careers in basic research.

\section{Incentivizing good science}

\section{What we want from scientists and science}

Participants identified three major classes of behaviors they wished to see in science (in order of popularity, Appendix 2D):

Honesty and integrity: Scientists should pursue the discovery of truth with honesty and integrity, and to the best of their ability; and should continue pushing the boundaries of human knowledge and asking new questions.

Communication and collaboration: Scientists should share information and ideas freely, both among the scientific community and outside of it. Transparency, openness, sharing, the free exchange of ideas and open dialogue among scientists were all identified as key attributes.

Utility and application of knowledge: Science should produce useful knowledge that can be applied in beneficial ways, with a responsibility to taxpayers to conduct this research with the greatest efficiency possible.

Participants proposed incentives to encourage the above behaviors:

Better training in research integrity: Responsible conduct of research education should begin early in graduate school, and ethics discussions should be commonplace.

Tracking investments in trainees: Funding agencies should maintain centralized information on trainee outcomes and make these data available to prospective trainees to encourage investment in students' and fellows' education.

New metrics of integrity: While current publication metrics encourage flashy publications, metrics should be created to reward integrity and honesty. These measures could include peer review contributions (whether pre- or post-publication); whether qualitative or quantitative, these could influence grant and job applications.

Open data and reducing the "minimal publishable unit": Journals could require data uploads prior to publication and raw data access during revision and/or following publication. This would encourage careful record-keeping and unbiased analysis through the scientific process. Furthermore, many results (especially negative and contradictory results) could be published under new models that do not require the time and resource investment of a traditional paper.

\section{Proposed solutions}

\section{Individual graduate students and postdocs}

- Graduate students and postdocs should be able to anonymously provide feedback on their training experiences and outcomes, ideally using the IDP as a framework.

\section{PIs and research groups}

- Open data access policies and publication of negative results should be encouraged.

\section{Institutions}

- Adequate training on the responsible conduct of research and critical thinking skills should be provided.

- Anonymous evaluation of available training by graduate students and trainees should be aggregated at the departmental level and used to form part of a training score for the department and institution.

\section{Funding agencies and the scientific community}

- Metrics of community-minded behavior (publishing negative results, peer review activity) should be taken into account when awarding grants.

- A website should be established to track graduate student and postdoc outcomes across institutions.

- A training score for departments and institutions should be considered during grant review.

\section{Conclusions}

The output of this workshop was a call by young researchers for incentivization of transparency and honesty in science, by developing new metrics and possibly incorporating these criteria into funding mechanisms. In particular, we propose the creation of a website for trainees to anonymously publish feedback on their training experiences and outcomes, ideally using the IDP (Fuhrmann et al., n.d.) as a framework. Trainees might complete an IDP, then later return to the site to report on their progress. Data, aggregated at the departmental or program level, would form part of a training score for the department and institution. This would permit prospective students and fellows to factor this information into their career decisions, thereby rewarding institutions that place an emphasis on training with improved student and fellow recruitment. Incorporating this score into the grant review process would encourage departments to invest in training. The website could also facilitate publication of institutions' training plans that outlines available career development opportunities. This could encourage the creation of de facto universal standards for training.

\section{Symposium organization}

The Future of Research Symposium was organized by a group of postdoctoral scholars from universities in the Boston area, including Boston University, Harvard University, Harvard Medical School, Tufts University, Brigham and Women's Hospital, the Massachusetts Institute of Technology, Brandeis University, and the 
Dana Farber Cancer Institute. The symposium was hosted at Boston University through a partnership with Boston University's Graduate Women in Science and Engineering (GWISE).

Speakers from academia and industry who have led national discussions participated. Henry Bourne opened the symposium with a keynote outlining the changes he thinks must be made to the scientific infrastructure. A panel comprising Sibby Anderson-Thompkins (Director, Office of Postdoctoral Affairs, University of North Carolina at Chapel Hill), Galit Lahav (Associate Professor, Harvard Medical School), Graham Walker (American Cancer Society Professor, HHMI Professor, Massachusetts Institute of Technology), David Glass (Executive Director, Novartis Institutes for Biomedical Research), and Richard Roberts (Chief Scientific Officer, New England Biolabs) summarized weaknesses and potential improvements in the current training system. A second panel comprising Marc Kirschner (John Franklin Enders University Professor of Systems Biology, Harvard Medical School), Michael Teitelbaum (Senior Research Associate, Harvard Law School), Naomi Rosenberg (Dean of the Sackler School of Graduate Biomedical Sciences, Tufts University), and Cynthia Furhmann (Dean of Career \& Professional Development in the Graduate School of Biomedical Sciences, University of Massachusetts Medical School) discussed issues pertaining to the scientific workforce and their implications for the future of science in the United States.

At the end of each workshop, participants were asked to fill out a short exit survey (full text in Appendix 3; individual comments from each workshop in Appendices 3A-D). The survey was designed to address three objectives. First, in order to assess how well the workshop format was working and how it could be improved, participants were asked to rate on a five-point scale how well the session addressed the stated objective, and how well they were able to arrive at meaningful solutions.

The second objective of the exit survey was to determine whether or not participants felt they had reached a consensus during the workshop, and to gauge the importance participants placed on reaching consensus about these issues. As the primary official report arising from a symposium intended to give voice to early-career scientists, this document should reflect the views expressed at the conference. However, it was unclear whether that aim would be best accomplished by representing all or most of the opinions expressed during the workshops, or by presenting only those ideas about which participants had reached consensus. Participants were therefore asked to rate on a five-point scale whether or not their group reached a consensus and how important they thought it was to have either a consensus or a diversity of views regarding these issues.

Finally, we asked participants to list any specific suggestions they might have about next steps to be taken after the symposium, such as ideas about people or organizations we should contact. The results of the survey are summarized in Figure 2. The survey indicated that participants cared both about reaching a consensus and having a diversity of ideas. Participants also indicated that the workshops were more successful in generating multiple solutions than in finding unanimity.
Workshop: Training Funding

How well did this session address the stated objective?
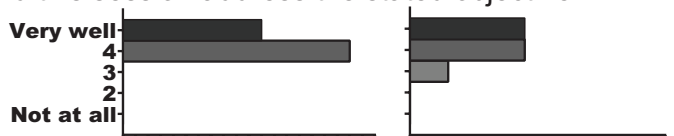

Were you able to arrive at meaningful solutions?
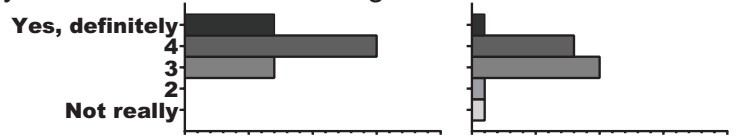

Did your group reach a consensus, or a diversity of views?
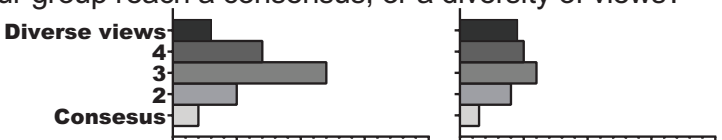

How important is it for us to have Consensus?
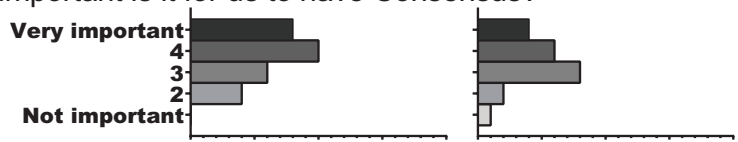

How important is it for us to have Diversity of Views?
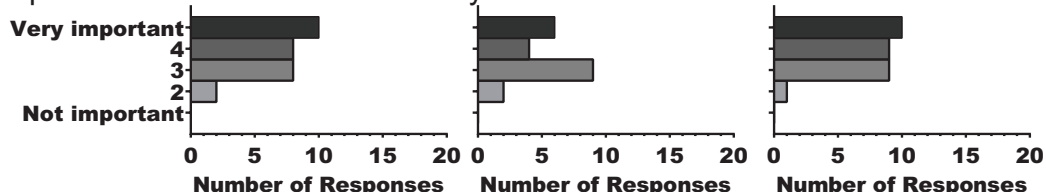

Workforce
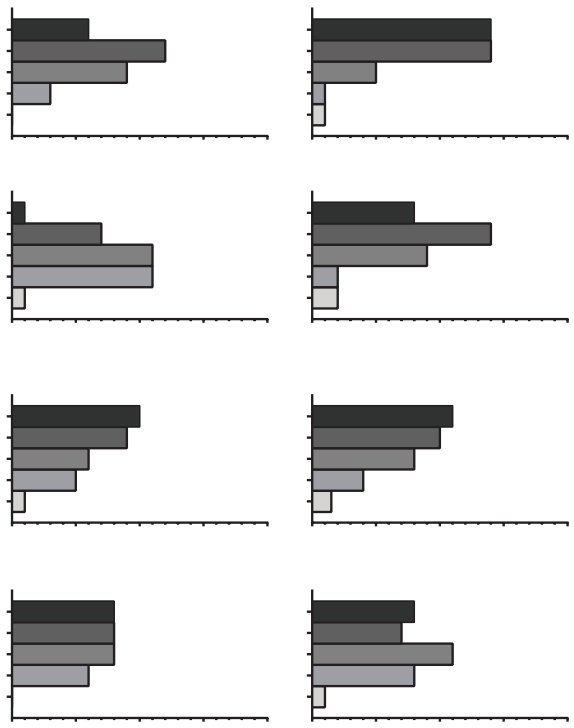

Figure 2. Workshop exit survey quantitative responses. 
While we did not strictly monitor the attendance at the symposium, registration data suggested that the majority of participants were postdocs and graduate students. Of 658 registrants, 344 were postdocs, 140 were graduate students, and the remainder included a mix of professors, instructors, journalists, administrators, research technicians, and research scientists from both academia and industry.

For detailed information on the requirements for preparing a symposium please see: The Logistics of Organizing the Future of Research Symposium (Mazzilli et al., 2014).

\section{Media response and online discussion}

The symposium received a wide variety of feedback and responses during and after the event, from both social media and the press, which continues to foster discussion.
During the symposium we engaged a large number of participants, both local and remote, using the \#FORsymp hashtag on twitter, and the @FORsymp twitter account, to leave comments and ask questions. Figure 3 shows examples of significant tweets and questions received during the symposium. A collection of salient moments from the symposium was also gathered by Alberto Roca (@minoritypostdoc) into a Storify (Roca, 2014).

Comments were also received from interested non-local parties and the symposium was particularly well tracked in the UK and Australia, as illustrated in Figure 4. The comments reinforced that these problems are not unique to Boston or the US; this is part of the discussion we hoped to generate further afield.

Immediately after the symposium, significant attention was focused on the Future of Research in the publication of an article by

Adam Carte @adamcarte. Oct 2

David Glass from @NovartisScience emphasizing that you can still do good

science and get published in an industry position \#FORsymp

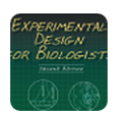

David J Glass@davidjglassMD. Oct 3

Tried to emphasize that before everything else comes quality and reproducibility.

Without that nothing matters.

\#FORsymp

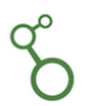

the Node@the_Node.Oct 3

Postdocs get together to discuss what needs to change in science at

@FORsymp. Follow the discussion with \#FORSymp!

F1000Research@F1000Research.Oct 3

The Future of Research Symposium is happening today. Follow \#FORsymp to see tweets from the meeting.

\section{Joanne Kamens@JKamens. Oct 2}

Postdocs in Boston planned a conference by Postdocs for Postdocs learn about it here-now happening ow.ly/ARLvd \#FORsymp

nationalpostdoc@nationalpostdoc. Oct 3

RT@FanuelMuindi: \#FORsymp: excited for this conference! It's about time we talk about the future of research \#STEM

becky ward@bwardboston. Oct 3

Question from the floor getting at the question of whether competition in science is fair - do the best and brightest survive? \#forsymp

Figure 3. Examples of significant tweets and questions from the symposium.

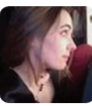

Michelle Brook@MLBrook. Oct 3

Science policy \& HE types - you may be interested to look at the \#FORsymp

hashtag. Some US post docs are running a meeting exploring issues

2.Dr Krystal @dr_krystal. Oct 2

Hey Aussie early/mid career researchers, check out this awesome "Future of

research" event, @FORsymp Lead by postdocs for postdocs \#forsymp

biochem belle@biochembelle · Oct 2

Henry Bourne now talking at the Future of Research Symposium in Boston.

Follow \#forsymp for more. (I'm not there, following via Twitter).

Figure 4. International interest over twitter. 
Carolyn Johnson in the Boston Globe, "Glut of postdoc researchers stirs quiet crisis in science" (Johnson, 2014). The article remained the most viewed on the Boston Globe website for several days thereafter and generated a wide range of responses, including comments on the article itself:

"Not only is it unconscionable that these highly educated scientists - after being encouraged to pursue PhD's by universities that know what career path difficulties lie ahead including years of being paid paltry annual salaries starting as low as $\$ 42,000$, but it also makes being able to live a decent lifestyle and repaying their student debt impossible; now unforgivable even by bankruptcy".

"Boom-and-bust syndromes have plagued science and engineering markets for at least fifty years. Over and over, we've heard laments like those in the current article. Yet little, if anything, seems to have changed for the better. The problems, and the lack of genuine progress, have been vexing".

"One possible partial solution would be to treat academic research groups as long-term productive teams. Pay post-docs what they're worth, and make their positions permanent midlevel research positions. There's plenty of people in the pipeline who love doing science who don't really want to be the head of their own lab, but we're trained as though that's the only option".

The Boston Globe itself compiled a Storify (The Boston Globe, 2014) on responses to the article from social media, particularly through use of the hashtag \#lifeafterPhD, and published additional opinion pieces, including "Let's change the system for postdocs" and "Postdocs in limbo? Expand your options" (Fuentes-Medel, 2014; Kirshenbaum, 2014).

The article also generated further discussion on reddit:

"I think it is fairly absurd that the NIH estimate for number of postdocs working in the US has an error of $\pm 15,500$ people".

"Is it far-fetched to think that academia is headed toward a tipping point? Under the current situation, nobody currently in grad school or academia more broadly is going to recommend STEM as a career path to anyone, in particular their children".

"It's frustrating because being a scientist is advertised as a stable job to people at every level of the education system until you're actually in grad school".

There was also significant commentary on Slashdot:

"If there was a genuine shortage [in STEM], you'd see sharp increases in salary levels. There's just a shortage of qualified people willing to work for much less than they're worth".

"Historically university posts were open to people with a BA (e.g. John Wesley and John Newman at Oxford in the 18th and 19th century). That it now takes a PhD and post doctoral work to get the same post means that we are training too many. Therefore the only solution is to row back on the PhDs being generated; given that governments are looking for money saving measures, this would seem an obvious starting point".

"It's crazy that we have these vast hordes of people trained up and desperate to work hard for scientific progress. But our economy can't find a way to provide them with jobs doing science".

Conversations on the LinkedIn group "PhD Careers Outside Academia", "The Postdoc Holding Tank" on October 5 $5^{\text {th }}$ and "What we already know..." on October 9th reiterated that this is not a new problem; the comments highlighted the dismal outlook among members of the community stemming from the lack of progress over the last decade. However, it is this very lack of change and the wider appreciation of the problem outside the academic community that we wish to target with the symposium and the publication of this document.

In the aftermath of the symposium, significant attention has been drawn to the event in academic media: in "Postdocs Speak Up" (Benderly, 2014), Science Careers magazine discussed the role of postdocs in advocating for themselves; an interview was featured in the scientific podcast Beta Sandwich; and the National Postdoctoral Association published an article about the symposium in its publication, the POSTDOCket.

We intend to continue bringing this conversation into the graduate student and postdoc community. Already, a poster (McDowell et al., 2014b) has been presented at the Out to Innovate 2014 Conference held by the National Organization of Gay and Lesbian Scientists and Technical Professionals, Inc. (NOGLSTP) and Out in Science, Technology, Engineering, and Mathematics, Inc. (oSTEM) at Georgia Tech (Atlanta, GA, November 8-9, 2014). The poster, which won the Leadership Poster Prize, generated a great deal of discussion regarding the intersection between postdoc and graduate student issues and issues facing underrepresented minorities.

Dataset 1. Dataset of Future of Research Symposium

http://dx.doi.org/10.5256/f1000research.5878.d39822

Legends describing each file can be found in the text file provided.

\section{Conclusion}

The workshops represented an opportunity for junior scientists to come together and discuss problems with the current scientific enterprise, and they produced an abundance of suggested solutions. Given the limited time of the workshops and the varied background of the participants in terms of their perspective on the current system and its challenges, a consensus on specific steps to be taken was not achieved. There were, however, certain common themes that require further discussion; because of the interconnected nature of these issues, affecting change will require a deeper understanding of both the causes of the problems and the effects of the proposed solutions. As a starting point for a larger and longer discussion, we 
have distilled three main proposals from the workshops and continued discussions among the organizers that can be implemented at all levels, from individual postdocs to institutions such as the NIH.

First, we recommend increased connectivity among junior scientists as well as between junior scientists and other segments of the scientific community. Postdocs and graduate students frequently conduct their research in isolation, as their work is rewarded primarily upon the basis of its novelty and independence, and as they are all competitors for a vanishingly small pool of advanced academic positions. The sense of isolation is particularly strong among postdocs, as many uproot themselves from their professional networks to take positions in geographically distant institutions without an accompanying cohort (such as in graduate school). This isolation precludes awareness of larger institutional issues and makes it more difficult for postdocs to advocate for themselves and bring about positive change. Postdocs and graduate students also must connect with other stakeholders in science so as to participate in the ongoing discussions about changes in training, funding, and other important policy issues. Finally, postdocs and graduate students should come together to define their position as major stakeholders in the research enterprise. While as individuals, junior scientists are temporary, replaceable, and largely anonymous, together they constitute the engine of the academic workforce. As such, they need to take collective action to ensure that their interests are protected as they work to maximize scientific output and efficiency (Cain et al., 2014). Only by bringing all stakeholders together will science be able to effectively grow and adapt to current and future challenges.

Second, we recommend increased transparency in trainee numbers and outcomes. Currently, national conversations decrying the "STEM shortage", as well as a lack of accessible information about the state of the workforce, create skewed perceptions regarding the demand for PhDs among many beginning biomedical graduate students. Students may become aware of the pyramidal structure of the academic workforce only late in their training. To remedy this, the number of graduate students and postdocs at all institutions should be made publicly available, together with information on career outcomes. Collecting and publishing information on career outcomes should be made a condition of an institution receiving NIH funding. Many institutions already collect this information at regular intervals, but lack a centralizing node to distribute it, and to compare the effect of their leadership. These organizations have a moral imperative to share this information; its dissemination will enable informed career and policy decisions. In addition, former students and postdocs should have a forum in which to anonymously report the outcomes of their training and subsequent career moves. Furthermore, there is a significant need to better define the role and purpose of the postdoc position. We advocate for transparency in terms of defining expectations of the balance between employment and training in individual postdoc appointments.

Finally, we call for increased investment in postdocs through financial independence from PI research grants and increased accountability for the quality of postdoc training. Currently, many postdocs have little power to freely pursue creative research directions and individual professional development plans, or to negotiate for necessary employment benefits. We propose two possible mechanisms for increasing postdoc autonomy. First, postdocs should not be supported by research grants, but rather exclusively by individual training fellowships. With this increased intellectual independence, postdocs would be allowed to pursue projects of mutual interest to themselves and their mentors. This creates a much-needed line between staff scientists and technicians, who may be paid and directed by research grants, and postdoctoral scholars, who should be focused on training and development. Second, the institutions employing, and the agencies funding, postdocs should seek increased accountability for their training through direct postdoc feedback to the funding agency. These reports of training experience and support given by PIs, departments, and institutions should be used in evaluating grants for award and renewal. Furthermore, some of this information, properly anonymized and aggregated, could be used to create a publicly accessible "training score" for departments; this metric would incentivize excellence in mentoring to maintain competitiveness in recruitment of young, talented scientists.

As the source of future scientific leadership, postdocs and graduate students are uniquely placed to influence the direction and culture of the research enterprise. To be most effective, however, we must educate ourselves about the prevailing conditions affecting the workforce and sustainability of research, and their historical and institutional bases. The voices of junior researchers must command a greater audience in the present discussion; additionally, as we take our places as the next generation of independent academic scientists, we can influence the culture, efficiency, and integrity of research from within. From both the attendance at the symposium and the ongoing coverage of the event and issues discussed, it is clear that junior scientists are invested in and passionate about these issues. We all must now rise to the challenge of taking action to build a sustainable, productive, and equitable scientific community.

\section{Data availability}

F1000Research: Dataset 1. Dataset of Future of Research Symposium, 10.5256/f1000research.5878.d39822 (McDowell et al., 2014d)

\section{Author contributions}

All authors were involved in the preparation and revision of the manuscript and have agreed to the final content.

\section{Competing interests}

No competing interests were disclosed.

\section{Grant information}

The author(s) declare that no grants were involved in supporting this work. The authors wish to thank our generous sponsors without whom the symposium would not have been possible: Novartis Institutes for Biomedical Research, the National Academy of Sciences, Harvard Medical School, the American Society for Cell Biology, the Harvard Medical School Postdoc Office, the Harvard Medical School Department of Systems Biology, the Harvard Medical School Department of Genetics, Monsanto Company Inc., Addgene, the Boston University Office of Professional Development and 
Postdoctoral Affairs, New England BioLabs Inc., the Tufts University Postdoctoral Office, Miltenyi Biotech, and Nature Jobs.

\section{Acknowledgements}

We are grateful for the time, counsel, and support of many advisors without whom the event would not have been possible. We are especially indebted to Becky Ward for inspiration and advice at every step of the way. We also thank Manu Sarna for teaching us how to moderate workshops, Henry Sauermann for advising us on surveys, Judy Glaven for feedback and perspective, Michelle Brook for guidance with blogging and social media, and David Cameron for assistance with promoting and framing the event. We are also grateful to Rosy Haskins, David Riglar, Dmitry Schvartsman and Ferdinando Pucci for their helpful comments on the manuscript.

We thank GWISE (Graduate Women in Science and Engineering) for partnering with us to host the event at Boston University (BU), Linda Hyman and the BU postdoc office, and the many BU administrators in financial offices that have and continue to support the symposium with their efforts.
Alberts B: Overbuilding research capacity. Science. 2010; 329(5997): 1257. PubMed Abstract | Publisher Full Text

Alberts B, Kirschner MW, Tilghman S, et al: Rescuing US biomedical research from its systemic flaws. Proc Natl Acad Sci U S A. 2014; 111(16): 5773-5777.

PubMed Abstract | Publisher Full Text | Free Full Text

Benderly BL: Postdocs Speak Up. Science Careers. 2014.

Publisher Full Text

Biomedical Research Workforce Working Group: Biomedical Research Workforce Working Group Report. (Report to the Advisory Committee to the Director). Bethesda, MD: National Institutes of Health. 2012.

Reference Source

Bourne HR: A fair deal for PhD students and postdocs. Elife. 2013a; 2: e01139. PubMed Abstract | Publisher Full Text | Free Full Text

Bourne HR: A recipe for mediocrity and disaster, in five axioms. Elife. 2013b; 2 e01138.

PubMed Abstract | Publisher Full Text | Free Full Text

Bourne HR: The writing on the wall. Elife. 2013c; 2: e00642.

PubMed Abstract | Publisher Full Text | Free Full Text

Bravo NR, Olsen KL: Letter to National Postdoctoral Association. 2007. Reference Source

Bush V: Science The Endless Frontier: A Report to to the President. Washington D.C.: United States Government Printing Office. 1945; 184.

Reference Source

Cain B, Budke JM, Wood KJ, et al:: How postdocs benefit from building a union. Elife. 2014; 3: e05614.

PubMed Abstract | Publisher Full Text | Free Full Text

Collins FS, Tabak LA: Policy: NIH plans to enhance reproducibility. Nature. 2014; 505(7485): 612-613.

PubMed Abstract | Publisher Full Text | Free Full Text

Ferguson K, Huang B, Beckman L, et al:: National Postdoctoral Association Institutional Policy Report 2014: Supporting and Developing Postdoctoral

Scholars. Washington, D.C.: National Postdoctoral Association. 2014.

Reference Source

Fuentes-Medel Y: Let's change the system for postdocs. The Boston Globe. 2014

Reference Source

Fuhrmann CN, Lindstaedt B, Hobin JA, et al.: myIDP Individual Development Plan 2014.

Reference Source

Harris R: When Scientists Give Up. NPR.org. 2014a.

Reference Source

Harris R: Too Few University Jobs For America's Young Scientists. NPR.org. 2014b.

Reference Source

Harris R: Top Scientists Suggest A Few Fixes For Medical Funding Crisis. NPR. org. 2014c.

Reference Source

Harris R: After The NIH Funding 'Euphoria' Comes The 'Hangover'. NPR.org. 2014d.

Reference Source

Hines WC, Su Y, Kuhn I, et al:: Sorting out the FACS: a devil in the details. Cell Rep. 2014; 6(5): 779-781.

PubMed Abstract | Publisher Full Text

Johnson CY: Glut of postdoc researchers stirs quiet crisis in science. The Boston Globe. 2014

Reference Source

Kirshenbaum S: Postdocs in limbo? Expand your options. The Boston Globe. 2014 Reference Source

Lang JM: Cheating Lessons: Learning From Academic Dishonesty. Cambridge,
Massachusetts: Harvard University Press. 2013.

Reference Source

Martinson BC: Universities and the money fix. Nature. 2007; 449(7159): 141-142. PubMed Abstract | Publisher Full Text

Mazzilli SA, Gunsalus KT, McDowell GS, et al.: Logistics of Organizing the FOR Symposium. The Winnower. 2014; 1. e141697.77958.

Publisher Full Text

McDowell G, Krukenberg K, Polka J: An open letter to AAAS journal "Science": Postdocs need to address "The Future of Research". The Winnower. 2014a. Publisher Full Text

McDowell GS, Krukenberg K, Polka J: The Future of Research Symposium. F1000Posters. 2014b.

Reference Source

McDowell G, Krukenberg K, Polka J: The Future of Research Symposium: Facilitating Postdoctoral Involvement in the Future of Science. Journal of Postdoctoral Research. 2014c; 2(9): 57-64.

Reference Source

McDowell GS, Gunsalus KTW, MacKellar DC, et al: Dataset of Future of Research Symposium. F1000Research. 2014d.

Data Source

National Research Council (US) Committee to Study the National Needs fo Biomedical, Behavioral, and Clinical Research Personnel. Research Training in the Biomedical, Behavioral, and Clinical Research Sciences. Washington (DC): National Academies Press (US). 2011.

Reference Source

National Science Board: Science and Engineering Indicators 2014. Arlington, VA: National Science Foundation, National Center for Science and Engineering Statistics. 2014

Reference Source

National Science Foundation: Selected Data on Graduate Students and Postdoctorates in Science and Engineering: Fall 1994, Supplementary Data Release Number 2: by Enrollment Status. (No. SRS 94-406). 1994.

Reference Source

National Science Foundation: Survey of Graduate Students and Postdoctorates in Science and Engineering, Fall 2012. National Center for Science and

Engineering Statistics. 2014

Reference Source

Nosek BA, Spies JR, Motyl M: Scientific Utopia II. Restructuring Incentives and Practices to Promote Truth Over Publishability. Perspect Psychol Sci. 2012; 7(6): 615-631.

Publisher Full Text

President's Council of Advisors on Science and Technology (PCAST) Public Meeting Transcript. President's Council of Advisors on Science and Technology (PCAST). 2014.

Reference Source

Roca A: \#FORsymp Future of Research symposium. 2014

Reference Source

Rockey S: Postdoctoral Researchers-Facts, Trends, and Gaps. 2012

Reference Source

Russo E: Victims of success. Nature. 2003; 422(6929): 354-355.

PubMed Abstract | Publisher Full Text

Rybarczyk B, Lerea L, Lund PK, et al.: Postdoctoral Training Aligned with the

Academic Professoriate. BioScience. 2011; 61(9): 699-705.

Publisher Full Text

Sauermann H, Roach M: Science PhD career preferences: levels, changes, and advisor encouragement. PLoS One. 2012; 7(5): e36307.

PubMed Abstract | Publisher Full Text | Free Full Text

Schillebeeckx M, Maricque $B$, Lewis $C$ : The missing piece to changing the university culture Nat Biotechnol. 2013; 31(10): 938-941.

PubMed Abstract | Publisher Full Text 
Sovacool BK: Exploring Scientific Misconduct: Isolated Individuals, Impure Institutions, or an Inevitable Idiom of Modern Science? J Bioeth Inq. 2008; 5(4) 271-282.

Publisher Full Text

Stephan P: How Economics Shapes Science. Cambridge, MA: Harvard University Press. 2012a.

Reference Source

Stephan P: Research efficiency: Perverse incentives. Nature. 2012b; 484(7392): $29-31$.

PubMed Abstract | Publisher Full Text

Strategic Evaluations, Inc. Training in Education and Critical Research Skills

Program (TEACRS), Tufts University School of Medicine. A Comparison of Active Trainees' Research Progress. Durham, NC. 2014.

Teitelbaum MS: Research funding. Structural Disequilibria in Biomedical

Research. Science. 2008; 321(5889): 644-645.

PubMed Abstract | Publisher Full Text
The Boston Globe: Research community responds to "Glut of postdoc researchers stirs quiet crisis in science" by Carolyn Johnson. 2014. Reference Source

The National Postdoctoral Association Core Competencies Committee: (n.d.). The NPA Postdoctoral Core Competencies. National Postdoctoral Association. 2007-2009.

Reference Source

US. Office of Personnel Management. (n.d.). Locality Pay Area Definitions. 2014

Reference Source

van Dijk D, Manor O, Carey LB: Publication metrics and success on the academic job market. Curr Biol. 2014; 24(11): R516-R517.

PubMed Abstract | Publisher Full Text

Zinn H: A PEOPLE'S HISTORY of the UNITED STATES 1492-PRESENT. Time Apt. Group. 2014.

Reference Source 


\section{Open Peer Review}

\section{Current Peer Review Status:}

\section{Version 1}

Reviewer Report 11 December 2014

https://doi.org/10.5256/f1000research.6280.r6856

(c) 2014 Gibbs Jr. K. This is an open access peer review report distributed under the terms of the Creative Commons Attribution License, which permits unrestricted use, distribution, and reproduction in any medium, provided the original work is properly cited.

\section{Kenneth D. Gibbs Jr. \\ National Cancer Institute, Washington, DC, USA}

The report by McDonnell et al. aims to provide a summary of the Future of Research Postdoctoral Symposium that took place in October 2014. The work of this group is commendable, and has the potential to inform on-going policy debates about how to improve the research enterprise. The article has some interesting findings and recommendations. However, I feel there are two important issues that prevented me from accepting without reservation: focus and tone.

1. Focus. I found the manuscript, as written, very difficult to follow. My sense is that in an effort to be comprehensive, the focus became lost (as one who often writes long and unwieldy drafts, I have much sympathy). In my view, readability of the paper would be enhanced by organizing it in three sections:

Context/Background. Here the authors can use data and other policy reports to describe some of the structural changes that have occurred in biomedicine in the past few years (e.g. stalled funding, growing number of trainees, etc.). They can then couple these changes with some of the issues that have resulted from this (e.g. an increased sense of competition to a level where it's no longer helpful; the favoring of incremental science over exploration, etc.). From this point, they can say the purpose of this symposium: adding the voices of this groups of postdocs to the debate.

Symposium. Clearly and concisely describe the symposium. List the four or five major goals/foci of the symposium (likely the workgroups). Then, for each, use a table to describe: 1. The central issue, 2 . How postdocs describe the problem (only list the main points, and if possible include the percentages of postdocs conceptualizing the problem in that manner), and 3. The proposed solutions (with individual students, PIs/research groups, institutions, and funding agencies as their own column). Four charts would significantly enhance readability. All additional information can be put in the supplement.

Summary recommendations. This could include a very brief nod to the media coverage (most of that should be in the supplement), the recommendations (currently the conclusions), and future recommendations. 
2. Tone. The paper read as a policy report, editorial, and meeting minutes all as one. There are many points where the authors make declarative statements but don't offer any citations. Two examples of many include:

"Specifically, the hyper-competition that *we have all experienced*, which stunts scientific curiosity and productivity, breeds fabrication and carelessness in the publication of data, and leads to a waste of valuable resources and intellectual capital, must be alleviated." It is not clear that all have experienced this and would make these conclusions.

The paragraph starting with this sentence: "In spite of the number of years spent in preand postdoctoral training, *only a handful of scientists feel that they are adequately pre- pared for any job other than conducting research. ${ }^{*}$ While career preparation is highly variable, it is an overstatement to say "only a handful feel prepared" for careers outside of research.

The authors would be well served by making it clear when they are stating something that is a fact, versus when they are conveying the opinions of the participants. Additionally, sometimes the term "we" is used, and it's unclear who it is referring to-the paper's authors, FOR Symposium attendees, the broader research community. Please be clear to whom you are referring.

Finally, the manuscript has something that seemed to be a major contradiction. In the executive summary, the authors say their report "represents a united voice of young biomedical scientists, conveying our concerns about the sustainability of the research enterprise and our hopes for change." However, on at least two occasions, they describe the challenge in reaching consensus among FOR Symposium participants

"Overall, the respondents' concerns and criticisms centered on a few key themes; however, there was disagreement regarding which issues are most important to the future of groundbreaking and sustainable science."

"Participants also indicated that the workshops were more successful in generating multiple solutions than in finding unanimity."

Even if there is not a "uniform voice" the symposium findings are still important. Don't feel the need to overstate conclusions.

Again, I feel the work is important. I fully expect the authors will be able to address my comments, at which point I would enthusiastically approve it.

Competing Interests: No competing interests were disclosed.

\section{I confirm that I have read this submission and believe that I have an appropriate level of expertise to confirm that it is of an acceptable scientific standard, however I have significant reservations, as outlined above.}

Reviewer Report 09 December 2014

https://doi.org/10.5256/f1000research.6280.r6854

(C) 2014 Stephan P. This is an open access peer review report distributed under the terms of the Creative Commons Attribution License, which permits unrestricted use, distribution, and reproduction in any medium, provided the original work is properly cited. 


\section{Paula E. Stephan}

Georgia State University, Atlanta, GA, 30303, USA

The report provides an excellent portrayal of conditions faced by postdoctoral researchers and graduate students in the biomedical sciences in the United States and it makes a number of constructive suggestions for reforms that could make the system more "early career" friendly. For example, the authors advocate increased transparency so that doctoral students and postdoctoral scholars will know the career outcomes of those who proceeded them and a change in the ratio of individuals who staff labs between graduate students, postdocs, technicians and staff scientists. They also advocate a greater focus on facilitating the learning of soft skills while in training and a redirection of resources towards younger researchers and away from extremely senior researchers. (Over 7\% of all NIH R01 supported PIs are currently 66 or older and about $3 \%$ are 36 or younger.) I would add to this list an increase in the salary of postdoctoral trainees: the current system, with its low pay for postdoctoral researchers, actively encourages an over reliance on postdoctoral trainees in the lab. I would also shift support of graduate students to training grants and away from graduate research assistantships. This would allow more control over the quality of training and the number of individuals trained. I would also note, as someone who has studied the funding of science and the biomedical work force for many years, that Vannevar Bush's vision was to support graduate students and postdoctoral researchers on fellowships, not on graduate research assistantships. His vision was to train future researchers, not to provide support for trainees to staff labs during their years of training. It was only in the late 1950s and early 1960s that the system began to increasingly tilt towards supporting students as graduate research assistants. It is also interesting to remember that "over training" in the biomedical sciences has been a major issue for at least 40 years. As early as 1976, an NRC report concluded that a "slower rate of growth in the labor force in these fields [the biomedical sciences] was advisable." And in 1998, the NRC report, "Trends in the Early Careers of Life Scientists," chaired by Shirley Tilghman, called for restraint in the number of PhDs produced and increased use of training grants relative to graduate research assistantships.

Competing Interests: No competing interests were disclosed.

I confirm that I have read this submission and believe that I have an appropriate level of expertise to confirm that it is of an acceptable scientific standard. 
The benefits of publishing with F1000Research:

- Your article is published within days, with no editorial bias

- You can publish traditional articles, null/negative results, case reports, data notes and more

- The peer review process is transparent and collaborative

- Your article is indexed in PubMed after passing peer review

- Dedicated customer support at every stage

For pre-submission enquiries, contact research@f1000.com 